\title{
Strategies for tourism development in peripheral areas in the alpine area
}

\author{
U. Pröbstl \\ Department of Spatial, Landscape and Infrastructure Planning, \\ University of Natural Resources and Applied Life Sciences, BOKU, \\ Austria
}

\begin{abstract}
Overall, Central Europe is densely populated but a closer look at the alpine area shows a population decrease in many peripheral rural areas, with many young people leaving their homes in search of better job opportunities. Frequently rural tourism is suggested as a remedy that should enhance the local economy, create new jobs, strengthen the regional identity and finance the basic and advanced infrastructure. Regions, communities, tourism organizations and managers use various different strategies to strengthen their tourism offers or to develop new ones. Four of the most relevant models are identified and presented. Thereafter, the advantages and disadvantages of these conceptual models are discussed against the main political goal: a sustainable and stable regional development.

Keywords: rural tourism, conceptual frameworks, peripheral areas, sustainable development.
\end{abstract}

\section{Introduction}

Overall, Central Europe is densely populated. Core areas enjoy permanent growth around cities, but many rural, especially mountainous, areas are in decline. As a consequence, these rural areas face many negative effects as the younger generation leaves for better job opportunities. The disparities between the centre and the periphery increase further as rural areas frequently experience declining investments in public infrastructure, insufficient public transportation, a lack of qualified education and only basic social services. In some regions, the negative effects on the quality of life in rural areas can already be seen [1]. While 
the quality of infrastructure in peripheral areas declines, regional planning still promotes the concept of the equality of living conditions across a nation. Therefore, a change of paradigm is necessary if regional planning is to address the decline in peripheral areas pro-actively in an innovative manner, as opposed to the standard growth-oriented thinking promoted by most textbooks.

One very common approach to reducing these negative consequences comes with the continuous enhancement and development associated with tourism and recreation development in peripheral areas $[2,3]$. Rural tourism and nature based recreation is perceived as a vehicle to keep the rural areas still attractive and alive. In particular, the tourism branch is expected to enhance the local economy, create new jobs, strengthen the regional identity, as well as local brands, and finance the basic and advanced local infrastructure.

\section{Understanding rural tourism and its driving forces}

In the literature, "rural tourism" is mostly presented as a form of tourism that showcases the rural life, art, culture, nature and heritage at rural locations. Rural tourism is furthermore characterized by creating economic and social benefits for the local community. Under the umbrella of tourism, special niche types have emerged such as agricultural tourism, cultural tourism, nature tourism, adventure tourism, and eco-tourism. In contrast to conventional tourism, rural tourism is based on the preservation of culture, heritage and traditions $[4,5]$.

George et al. [3], Bell et al. [6] and Pröbstl et al. [7] describe new societal trends which will further strengthen rural tourism. One is demographic change, characterized by an increase of the elderly generation, which is very much attracted by nature and nature experience. This older generation is now much more mobile than any previous generations and they are interested in returning to their roots. They are also interested in a combination of wellness and nature based offers.

George et al. [3] explain this desire for returning to the roots as possible effects of globalization. The feeling of being lost in a globalized world is compensated by the retreat into one's own private sphere, the home and garden (so called "cocooning") and new demands in tourism for a special regional authenticity and environmentally sound offers. The choice of a tourism destination in rural areas could also enhance someone's search for the meaning of life, being active in nature as opposed to the triviality and strict functionality of modern urban life.

Despite this basic desire for the 'roots', rural tourism development nevertheless needs to fulfil the desires of an increasingly sophisticated consumer. The vacationer of the future expects perfection, including illusion building. In a paradoxical manner, destinations become increasingly similar and interchangeable, while the trend towards individuality increases. This offers advantages for rural tourism. The desire for authenticity and subjectively satisfactory experiences increases. 


\section{Methodological approach}

This paper will present several different types of tourism development in peripheral, rural areas in the alpine areas. In most cases, local communities and regions try to initiate, support or enhance the conditions for any form of tourism development. Chapter 4 will develop a typology of these possible development options by suggesting four models. The discussion in Chapter 5 will evaluate these four tourism development models based on a) an OECD document on "Tourism Strategies and Rural Development" [8]; and b) a paper by Meyer-Cech and Pröbstl [9], who summarize indicators for sustainable Tourism in mountainous regions.

The OECD document ([8]:14) suggests that rural tourism should be:

- Located in rural areas;

- Functionally rural, built upon the rural world's special features, small scale enterprise, open space, contact with nature and the natural world, heritage, traditional societies and traditional practices;

- Rural in scale - both in terms of buildings and settlements - and therefore, small scale;

- Traditional in character, growing slowly and organically, and connected with local families. It will often be very largely controlled locally a developed for the long term good of the area;

- Sustainable - in the sense that its development should help sustain the special rural character of an area and in the sense that its development should help sustainable in its use of resources. Rural tourism should be seen as a potential tool for conservation and sustainability, rather than as an urbanizing and development tool;

- Of many different kinds, representing the complex pattern of rural environment, economy and history.

Meyer-Cech and Pröbstl [9] list the following indicators of sustainable tourism in mountainous areas:

- Economic viability;

- A wise use of resources;

- The wellbeing of the host population;

- An intact local culture;

- An established short way of supplies; and

- A fostered regional identity.

The results of the evaluation will be compared and discussed.

\section{Conceptual framework}

A number of different approaches have been developed by regional administrations, tourism organizations and managers to strengthen rural tourism offers, or to develop new ones. This paper suggests that the many approaches can be characterized by four types: the "lighthouse model", the small scaled land use model, the zoning model and the linear model. These models have been 
generalized from case studies and it is important to emphasize that tourism in rural areas does not emerge by itself, but in the alpine context, as elsewhere, each model requires conscious decisions by the community early in the planning process. One additional goal of this paper is to clarify for community based decision makers that they should not simply focus on one single building code or master plan decision, but instead perceive and treat the development model and concept that inevitably is associated with a decision, including its possible consequences. Furthermore, these models could be seen as development options which could be seen as the bases of community planning and embedded tourism strategies.

\subsection{Model 1 "the lighthouse model"}

In the "lighthouse model", most of the rural landscape with its farms, traditions and culture remains unspoiled by tourism. The positive effect for new job opportunities and services in the rural countryside is created by one single large tourism project. Its positive spinoffs are widely spread over the rural landscape even though the project is located at one single location. The positive economic and social multiplier effects might also compensate possible negative effects on landscape beauty and natural integrity. New developments in the field of spa and wellness tourism in Austria show that the "lighthouse-effect is not necessarily limited to economic and service improvements for local people, but might add new architectural attraction to the region, associated with another opportunity for an aesthetic experience.

In the planning literature, this concept is frequently described in the context of gentrification. George et al. [3] illustrate both possible effects: the revitalization of rural areas or their degradation. Kennedy and Leonard [10] describe the possible degradation process which starts with the physical upgrading of the neighbourhood, the changing character of the housing stock and the beginning of a displacement process of original residents. Several alpine examples show, that the lighthouse model can enhance the existing landscape character as it supports the traditional land use with the opportunity for the direct selling of farm products, providing services like guided tours or seminars, and part time employment.
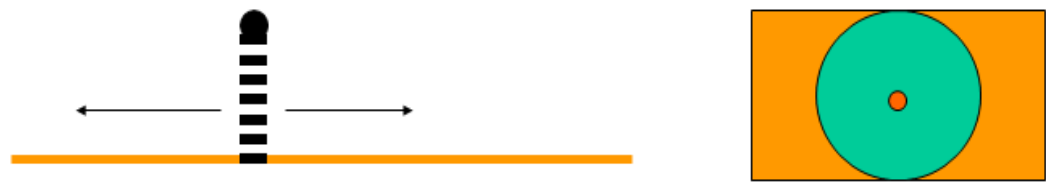

Figure 1: The "lighthouse model". 


\subsection{Model 2 "the small-scale land use related model"}

Most authors writing about rural tourism implicitly have this model in mind. Typical for this model is the integration of tourism into the existing agricultural land use. Many farmers are increasingly realising the additional economic benefits that can be gained from diversifying into providing farm stays on their land. Although the tourism infrastructure is mainly integrated in the existing operational farm structure, this model requires adaptation and life-style modification by the provider. The farm operation itself requires some administrative and economic adaptation, starting with building permits and permits for the tourism operation, financial investments to change the agricultural enterprise to a farm for guests and tourists (operational concerns also need to consider security, the design of guest houses, playground, a stable for a petting zoo). Some social adaptation will also be necessary. Dealing with guests, having them around all day and combining their presence with the household and farm work by the various family members is a challenge by itself. Finally, the working processes must be integrated and adapted to tourism business. These requirements often hinder a successful implementation and lower the interest of the local population for investing into rural tourism. From a social perspective, modern farmers perceive the separation between own family and guest quarters as another essential ingredient for success.

Outside the alpine area, this model is also quite successful. For example, in the UK, Devon Wildlife Trust have a number of approved farms such as the Organic Ashridge Farm [11] which offers bed and breakfast, or the Beer Mill Farm offering cottages and access to private nature trails [12]. In Australia, the popularity, of 'active' nature tourism such as staying on cattle ranches to take part in activities such as mustering cattle, natural horsemanship, sheep shearing and bushcraft is especially popular among backpackers [2].

\subsection{Model 3 "the zoning model"}

The alpine rural landscape is rich in biodiversity and valuable biotopes and habitats. Model 3 is based on the idea to market the outstanding natural integrity to tourists. One major precondition to sell this concept to tourists is to obtain a certificate for these valuable landscapes, and thereafter rural communities of this type promote the protected areas in their region.

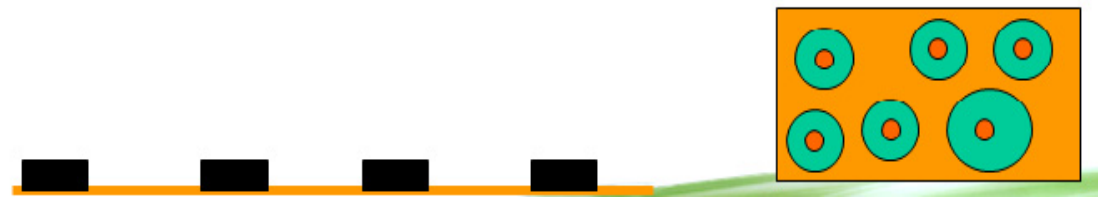

Figure 2: The land use related model is typically based on and integrated with agricultural land use. 

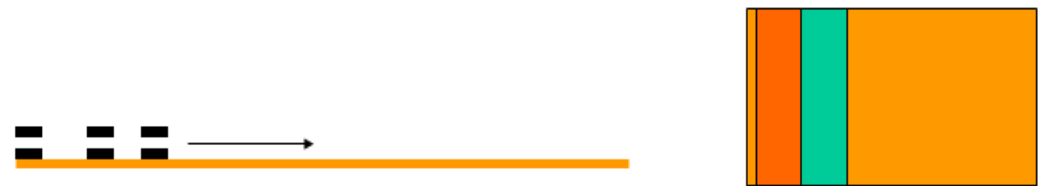

Figure 3: Schematic illustration of the zoning model.

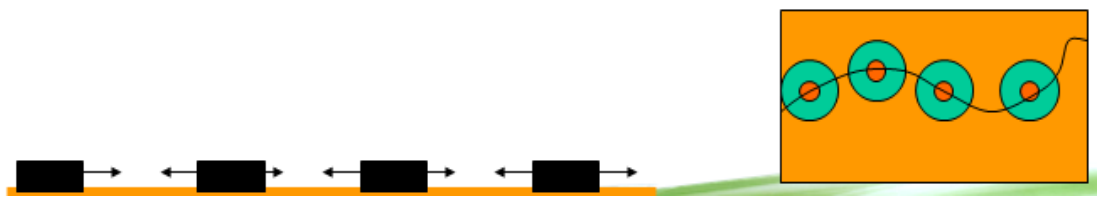

Figure 4: Schematic illustration of the "linear model".

Common to all approaches of this type is a zoning concept which allows the marketing special areas of diversity the habitat of endangered species or even the idea of remaining "wilderness". The concept is also often used in association with the European conservation system Natura 2000.

This usage of the concept of 'protected areas stands in stark contrast to North America where a 'protected area' is synonymous with the term 'park', as in a 'national park' or 'wilderness park' (IUCN categories I and II). In this context, rural tourism would be classified as ecotourism or nature based tourism. The European destinations however also use other IUCN categories of landscape protection for advertising the natural qualities of a region, and might actually use the name of the protected area for branding the entire region. Rural tourism destinations with zoning concepts can be found not only in National Parks but also in nature parks or Biosphere reserves, which fall under IUCN categories V and VI. Regardless of the status of protection of the area, as long as they have a conservation focus they can serve as a model for sustainability, as they balance ecological values of biodiversity, with the economic values of natural resources and community values. Many of these European examples manage to maintain traditional structures and forms of land use by integrating them into a unique tourism offer.

\subsection{Model 4 "linear concept"}

The "linear model" uses mostly existing structures, buildings, cultural aspects, religion, traditions or infrastructure ([4], S.162, [13]). The tourism concept connects this infrastructure to an entire product. Typical examples are a Castle Road, a Cheese Road, or the Iron Road in the alpine area [14].

With these linear concepts an already well-known rural countryside can be presented under new and often various themes and aspects such as the rich historical, cultural past or the insight in the history of land use traditions (alpine meadows-mountain huts-and-cheese making, cellars-winery-and-win yards). 
This concept is based on the positive effect of branding and theming. Following Morgan and Pritchard ([15]:61) one can think of brands as communication devices, as perceptual entities, as value enhancers and as relationships. Brands like the Castle-road in Styria (Austria) are used to convince the consumer or the potential consumer about the unique selling proposition of this product. Shaw and Williams [16] as well as Morgan and Prichard [15] underline that successful branding must create an emotional attachment for the potential tourist and it must be enthusing for local stakeholders and partners. This linear model guides the communities to focus on a clear concept and a niche addressed to the tourist, instead of presenting themselves as a region where you can experience everything culture, land use tradition and local events in a rural setting. The advantage is that several communities can cooperate to develop these products across a region. For the tourist the process of discovering "jewels" in the landscape is more attractive than other concepts such as local theme parks.

\section{Evaluation and discussion}

When evaluating these four models against the OECD criteria listed in section 3 above, it becomes obvious that all four models of rural tourism development offer the opportunity for a sustainable rural tourism - in the sense that the development will help sustain the special rural character and in the sense that its development will support the sustainable use of local resources.

At first glance, it appears that three of the four models (the small scale land use model, the zoning model and the linear model) all support the required rural functionality such as open space, contact with nature and the natural world, heritage, traditional societies and traditional practices. However, at closer inspection it becomes apparent that functionality is only given if one perceives these models in a rather nostalgic way. The required economic, social and cultural shifts have already been mentioned in the context of the land use model, but the linear and the zoning model also need professional concepts, branding and marketing. All of them can only survive if they are based on a communitybased cooperative planning process. In most cases these three models will fulfil the requirements of being "Rural in scale - both in terms of buildings and settlements" and of being traditional in character.

The "light house model" does not meet the set of evaluative criteria. It is typically based on larger buildings, construction on a new site, new jobs and new land uses (e.g. health trails) which are not in line with the OECD criteria. Whether negative effects on "the rural character in scale" occur will depend on the specific concept. If it is based on a long term master planning process of the community it should contribute to sustainable development. In contrast to the other models, the light house model provides the opportunity to address many of the structural problems of rural areas more so than any of the other models. This type of development will most likely offer different job opportunities for the younger generation including training and employment for positions in 
management and higher qualification. In many cases, the light house contributes to improved services (health service, medical care, recreational offers) to the region which adds significantly to the quality of life in rural areas.

When evaluating the four models along the argument provided by MeyerCech and Pröbstl [9], the differences between the four models appear to be less significant. All four models have good potential for providing economic viability and wise use of resources. The definition of the term "wellbeing of the host population" varies between the different concepts. It is the understanding of Meyer-Cech and Pröbstl [9] that in Central Europe wellbeing should include mobility, services, educational options as well as the economic and traditional background. It appears that all four concepts manage to keep local culture intact as long as the lighthouse is not dominating the existing land use but supporting it, e.g. establishing short way supplies, wine tasting events at the farms and other forms of cooperation.

All models could potentially foster the regional identity or jeopardize it. Especially the light house model, the zoning model and the linear model are dangerous when implemented in a top down approach instead of a community based cooperative planning process.

\section{Conclusion}

Rural tourism can be seen as a potential tool for sustainability, rather than as a development tool. Tourism business is experience oriented. In the past rural destinations and communities frequently made the mistake of promoting themselves as destinations where one finds everything: happy farmers, romantic churches, traditional land use, local culture and various traditions. However, such a general offer does not attract an experience oriented tourist who can only be enticed to visit by clearly defined concepts and desirable expected experiences. The demand of special target groups must be addressed by rural tourism offers. The purpose of the conceptual framework presented above is to support the understanding of rural tourism by the responsible decision making processes. The framework consisting of the four models underlines the importance of community control of tourism development given its invasive nature and its possible consequences.

When it comes to the evaluation of rural tourism concepts, one must be very careful not to fall into the "nostalgia trap". Dann [17] expressed four types of nostalgia: longing for paradise, the simple life, past times and the return to childhood. Schouten [18] argues in this context that these types of nostalgia all mean basically the same thing: an escape from the stress or tedium of ordinary life or in other words the wish to escape globalization.

Therefore, we suggest the use of more generic criteria to evaluate possible development models for rural areas such as the effects on economic viability, a wise use of resources, the wellbeing of the host population, an intact local culture, an established local network of supplies and a fostered regional identity. 


\section{References}

[1] Bätzing, W., 2000, Die Alpen. Geschichte und Zukunft einer europäischen Kulturlandschaft, München.

[2] Bell, S., Tyrväinen, L., Sievänen, T., Pröbstl, U., Murray, S., 2007, Outdoor recreation and Nature Tourism: A European Perspective Living Reviews in Landscape Research, 1, 2007, 2.

[3] George, E.W., Mair, H., Reid, D.G, 2009, Rural tourism development, Bristol, Buffalo, Toronto.

[4] Roberts, L., Hall, D., 2001, Rural Tourism and Recreation principles to practise, Oxon, UK.

[5] www.tourism.gov.in/policy/schrural.htm, accessed 10.3.2010.

[6] Bell, S., Murray, S., Tyrväinen, L., Sievänen, T., Pröbstl, U.(eds.), 2009, European Forest Recreation and Tourism, A Handbook, London, New York

[7] Pröbstl, U., Elands, B., Wirth, V., Bell, S., 2010, Management of Recreation and Nature based tourism in European Forests, Springer Science, Heidelberg.

[8] OECD, 1994, Tourism strategies and rural Development (pdf-document on www.oecd.org)

[9] Meyer-Cech, K. Pröbstl, U., 2006, Sustainable Tourism in mountainous regions. In: Brebbia, C.A. Pineda, F.D. (Eds.), Sustainable Tourism II, 239250; WIT Press, Southampton, Boston.

[10] Kennedy, M., Leonard, P., 2001, Dealing with Neighborhood Change: A Primer on gentrification and Policy Choices. A Discussion Paper. Washington: The Brooking Institute Centre on Urban and Metropolitan Policy.

[11] www.ashridgefarm.co.uk/ accessed 10.3.2010

[12] www.selfcateringcottagesdevon.co.uk, accessed 10.3.2010

[13] Weber, G., 2003, Touristische Themenstraßen, Institut für Raumplanung, BOKU, Wien

[14] Meyer-Cech, K., 2003, Themenstraßen als regionale Kooperationen und Mittel zur touristische Entwicklung - fünf österreichische Beispiele. Dissertation an der Universität für Bodenkultur, Wien.

[15] Morgan, N, Pritchard, A., 2004, Meeting the destination branding challenge. In N. Morgan, A. Pritchard and R. Pride (eds) Destination Branding: Creating the Unique Destination Proposition ( $2^{\text {nd }}$ edn, pp 59-78) Oxford.

[16] Shaw and Williams 2004, after [3]

[17] Dann, G., 1994, Tourism and nostalgia: Looking forward to going back. Vrijrtjid En Samenleving 1 (2), 65-74

[18] Schouten, F., 1996, Tourism and cultural change. Proceedings of a round table: Culture, Tourism Development: Crucial Issues for the XXIst Century, Paris. 